\title{
Influence of dihydralazine induced afterload reduction on systolic time intervals and echocardiography in healthy subjects
}

\author{
HEIKO C STERN, JENNIFER H MATTHEWS, GUSTAV G BELZ \\ From the Institute for Cardiovascular Therapy, Wiesbaden, West Germany
}

SUMMARY The influence of a pure afterload reduction on systolic time intervals and various echocardiographic indices was assessed in six healthy volunteers, who underwent a single blind placebo controlled trial of three regimens of intravenous dihydralazine $(6.25,12.5$, and $25.0 \mathrm{mg})$. Subsequently autonomic blockade (propranolol and atropine) was used to eliminate the influence of the autonomic reflex action during dosage with dihydralazine $6.25 \mathrm{mg}$. Dihydralazine increased heart rate to an extent depending on dose, decreased diastolic blood pressure, end systolic diameter, and end systolic wall stress, and enhanced fractional shortening and cardiac output. Heart rate corrected pre-ejection period was shortened and left ventricular ejection time was prolonged, whereas electromechanical systole remained virtually unchanged. Autonomic blockade eliminated dihydralazine's effect on heart rate and cardiac output; blood pressure and systolic wall stress fell appreciably, whereas dihydralazine-induced changes in the systolic time intervals were virtually unaffected.

Thus the present study indicates that regardless of the autonomic reflexes heart rate corrected pre-ejection period and left ventricular ejection time, but not electromechanical systole, are highly dependent on afterload, and this effect should be considered when systolic time intervals are evaluated.

Measuring systolic time intervals is a valuable noninvasive method of estimating the effects of drugs on the cardiovascular system. These measurements indicate variations in cardiac performance and, like other indices, are influenced not only by myocardial contractility itself but also by preload, afterload, and heart rate. ${ }^{1}$ Changes in systolic time intervals induced by pharmacological agents may therefore be produced by any of these influences alone or in combination. To evaluate these changes comprehensive knowledge is required of how these time intervals are affected in specific haemodynamic situations. The influence of heart rate can easily be eliminated using the correction formulas of Weissler et al. ${ }^{2}$ The influence of preload changes is fairly well established and can be confirmed by simultaneous echocardiographic measurements of

Requests for reprints to Professor Gustav G Belz, Wilhelmstrasse 16, D-6200 Wiesbaden, West Germany.

Accepted for publication 26 April 1984 left ventricular end diastolic diameters. ${ }^{3}$ It is not yet known how systolic time intervals are affected by afterload variations; earlier observations are not entirely conclusive..$^{4}$ In a recent study investigators attempted to assess changes in systolic time intervals after a reduction in afterload with terbutaline; ${ }^{6}$, however, additional direct cardiac interference by beta ${ }_{2}$ sympathomimetic activity ${ }^{7}$ may have affected the results.

We studied the changes in systolic time intervals resulting from a pure afterload reduction with dihydralazine (hydralazine). In addition autonomic blockade $^{8}$ was induced to differentiate between the vasodilator's intrinsic properties and reflex mediated reactions.

\section{Subjects and methods}

We selected three female and three male healthy volunteers with good quality echocardiographic tracings of the left ventricle and a supine systolic blood pres- 
sure $>110 \mathrm{~mm} \mathrm{Hg}$. Mean (SD) age was $25.7(2 \cdot 3)$ years, weight $65.4(8.2) \mathrm{kg}$, and height $172.8(8.6) \mathrm{cm}$. Informed written consent was given.

\section{TRIAL PROTOCOL}

The study was a randomised, single blind, intraindividual, placebo controlled trial. On each of six test days the subjects received two intravenous infusions. The first infusion contained $25 \mathrm{ml}$ of $0.9 \%$ saline but on one day it contained $0.04 \mathrm{mg}$ atropine $/ \mathrm{kg}$ and $\mathbf{0 . 2}$ $\mathrm{mg}$ propranolol $/ \mathrm{kg}$ in saline to induce autonomic blockade during the trial period ${ }^{8}$; the infusion rate was adjusted to give $1.0 \mathrm{mg}$ propranolol $/ \mathrm{min}$. The second infusion contained either dihydralazine diluted with $0.9 \%$ saline to a volume of $50 \mathrm{ml}$ or a placebo ( $50 \mathrm{ml}$ saline $0.9 \%$ ); this infusion was started eight minutes after the first infusion ended and lasted 10 minutes. All the infusions were delivered by an automatic perfusor pump (Braun, Melsungen). Thus on four days each subject received a single dihydralazine dose or placebo, the dihydralazine doses being $6.25 \mathrm{mg}, 12.5 \mathrm{mg}$, or $25.0 \mathrm{mg}$. On one day a single dose of $6.25 \mathrm{mg}$ was given after the autonomic blockade and for control purposes a placebo infusion alone and autonomic blockade alone was given on one day each. A minimum 72 hour washout period was allowed between the test days.

The evening before each test day the subject was restricted in activity and food intake. ${ }^{9}$ The subject arrived at our laboratories between 0800 and $1200 \mathrm{~h}$ in a fasting state. An indwelling venous cannula was inserted and the subject laid in the supine position (head elevated $15^{\circ}$ ) for a 15 minute rest period. Two sets of control data were recorded five minutes apart, and their mean values termed baseline 1; the first infusion followed these measurements. A further set of data (baseline 2) was recorded five minutes after the end of the infusion, and three minutes later the second infusion of the daily single dihydralazine dose was given and lasted 10 minutes, the end of this infusion being the zero time point. Serial data were recorded at $2,5,10,20,30$, and 40 minutes after dihydralazine.

\section{MEASUREMENTS AND CALCULATIONS}

Electrocardiogram (CM5), phonocardiogram, and carotid pulse curves were recorded simultaneously using a Cardirex 3T (Siemens Elema) jet recorder. Systolic time intervals were recorded as described.910 Heart rate corrections were done using Weissler et al's equations, ${ }^{2}$ and the difference between the measured and the predicted value gave the corrected value. Blood pressure was measured using an ordinary cuff mercury manometer. $M$ mode left ventricular echocardiograms were recorded simultaneously with the measurements of the systolic time intervals using standard techniques. ${ }^{911}$
Table Mean (SD) values before any drug infusion (baseline 1) and five minutes after autonomic blockade or placebo infusion (baseline 2) before the administration of dihydralazine

\begin{tabular}{|c|c|c|}
\hline $\begin{array}{l}\text { Haemodynamic indices and } \\
\text { drug regimen }\end{array}$ & Baseline 1 & Baseline 2 \\
\hline $\begin{array}{l}\text { Heart rate (beats/min) } \\
\text { A } \\
\text { B } \\
\text { C } \\
\text { D }\end{array}$ & $\begin{array}{l}60.4(10.1) \\
64.8(6.9) \\
62.0(6.3) \\
57.0(7.8)\end{array}$ & $\begin{array}{l}97.1(13.6) \\
63.0(6.6) \\
62.0(10.9) \\
57.4(8.6)\end{array}$ \\
\hline $\begin{array}{l}\text { Systolic blood pressure (m } \\
\text { A } \\
\text { B } \\
\text { C } \\
\text { D }\end{array}$ & $\begin{array}{l}120.3(8.7) \\
123.1(8.7) \\
124.2(10.2) \\
122.4(7.5)\end{array}$ & $\begin{array}{l}128.0(9.4) \\
123.7(9.5) \\
124.3(8.7) \\
122.0(9.7)\end{array}$ \\
\hline $\begin{array}{l}\text { Diastolic blood pressure ( } \\
\text { A } \\
\text { B } \\
\text { C } \\
\text { D }\end{array}$ & $\begin{array}{l}78.7(6.5) \\
80.7(6.8) \\
83.0(4.4) \\
81.3(5.7)\end{array}$ & $\begin{array}{l}89.0(8.2) \\
81.2(8.4) \\
83.3(5.3) \\
80.8(9.1)\end{array}$ \\
\hline $\begin{array}{l}\text { Stroke volume }(\mathrm{ml}) \\
\text { A } \\
\text { B } \\
\text { C. } \\
\text { D }\end{array}$ & $\begin{array}{l}72.6(12.6) \\
69.8(8 \cdot 2) \\
68 \cdot 3(9.8) \\
66 \cdot 2(11 \cdot 7)\end{array}$ & $\begin{array}{l}65.5(17.5) \\
71.1(6.3) \\
68.6(9.8) \\
66.8(16 \cdot 3)\end{array}$ \\
\hline $\begin{array}{l}\text { Cardiac output }(1 / \mathrm{min}) \\
\text { A } \\
\text { B } \\
\text { C } \\
\text { D }\end{array}$ & $\begin{array}{l}4.38(0.11) \\
4.52(0.83) \\
4.24(0.75) \\
3.75(0.82)\end{array}$ & $\begin{array}{l}6.34(1.90) \\
4.48(0.63) \\
4.27(1.02) \\
3.83(1.13)\end{array}$ \\
\hline $\begin{array}{l}\text { Total peripheral resistance } \\
\text { (dyn s } \mathrm{cm}^{-5} \text { ) } \\
\text { A } \\
\text { B } \\
\text { C } \\
\text { D }\end{array}$ & $\begin{array}{l}1783.5(356.2) \\
1729.3(228.1) \\
1913.5(346.7) \\
2186.4(422.0)\end{array}$ & $\begin{array}{l}1385 \cdot 1(363 \cdot 7) \\
1734.3(146.6) \\
1911.4(410 \cdot 0) \\
2100.2(494 \cdot 2)\end{array}$ \\
\hline $\begin{array}{l}\text { End systolic diameter (cm) } \\
\text { A } \\
\text { B } \\
\text { C } \\
\text { D }\end{array}$ & $\begin{array}{l}3.30(0.33) \\
3.35(0.27) \\
3.19(0.35) \\
3.36(0.31)\end{array}$ & $\begin{array}{l}3.32(0.39) \\
3.37(0.29) \\
3.25(0.39) \\
3.30(0.32)\end{array}$ \\
\hline $\begin{array}{l}\text { Fractional shortening (\%) } \\
\text { A } \\
\text { B } \\
\text { C } \\
\text { D }\end{array}$ & $\begin{array}{l}33.6(5.5) \\
32.3(3.2) \\
34.0(4.7) \\
31.2(4.0)\end{array}$ & $\begin{array}{l}31.3(6.9) \\
32.8(2.6) \\
33.6(4.6) \\
32.1(5.5)\end{array}$ \\
\hline $\begin{array}{l}\text { End systolic wall stress } \\
\left(10^{3} \mathrm{dyn}^{-2}\right) \\
\text { A } \\
\text { B } \\
\text { C } \\
\text { D }\end{array}$ & $\begin{array}{l}54.99(15.5) \\
49.70(6.0) \\
50.99(16.0) \\
65.41(8.4)\end{array}$ & $\begin{array}{l}60.82(20.6) \\
49.20(5.2) \\
52.40(15.3) \\
61.67(11.4)\end{array}$ \\
\hline $\begin{array}{l}\text { Pre-ejection period (correc } \\
\text { A } \\
\text { B } \\
\text { C } \\
\text { D }\end{array}$ & $\begin{array}{l}-2 \cdot 6(12.9) \\
-1.7(6 \cdot 0) \\
4.7(7.9) \\
5.7(8 \cdot 5)\end{array}$ & $\begin{array}{l}11.4(7 \cdot 1) \\
3.0(4 \cdot 8) \\
2.1(10.5) \\
-0.9(15.4)\end{array}$ \\
\hline $\begin{array}{l}\text { Left ventricular ejection ti } \\
\text { (corrected) (ms) } \\
\text { A } \\
\text { B } \\
\text { C } \\
\text { D }\end{array}$ & $\begin{array}{l}-16.0(13.3) \\
-15.3(11.8) \\
-17.2(8.3) \\
-15.4(11.8)\end{array}$ & $\begin{array}{l}-0.5(17.3) \\
-15.4(16.6) \\
-14.3(9.9) \\
-8.4(13.4)\end{array}$ \\
\hline $\begin{array}{l}\text { Electromechanical systole } \\
\text { (corrected) (ms) } \\
\text { A } \\
\text { B } \\
\text { C } \\
\text { D }\end{array}$ & $\begin{array}{l}-18.6(12.1) \\
-17.0(10.5) \\
-12.6(5.4) \\
-9.3(9.7)\end{array}$ & $\begin{array}{l}10.9(17.9) \\
-15 \cdot 2(11.0) \\
-12.2(4.4) \\
-8.9(20.6)\end{array}$ \\
\hline
\end{tabular}

$\star \mathrm{A}$, autonomic blockade plus $6.25 \mathrm{mg}$ dihydralazine; B, $6.25 \mathrm{mg}$ dihydralazine; $C, 12.5 \mathrm{mg}$ dihydralazine; $\mathrm{D}, 25 \mathrm{mg}$ dihydralazine. 
Mean end diastolic (EDD) and end systolic diameters (ESD) were measured over five cardiac cycles. Stroke volume and cardiac output were calculated using ventricular volumes, ${ }^{12}$ and total peripheral resistance was calculated using standard equations ${ }^{13}$; fractional shortening (\%) was equal to ((EDD-ESD)/ EDD) $\times 100$; and end systolic wall stress $\left(10^{3}\right.$ dyn $\left.\mathrm{cm}^{-2}\right)$ was equal to $(0.334)(\mathrm{P})(\mathrm{ESD}) / \mathrm{H}(1+(\mathrm{H} /$ ESD) $)^{14-16}$ where $\mathrm{H}$ is the posterior wall thickness at end systole and $P$ is the systolic blood pressure.

\section{STATISTICS}

Student's $t$ test for paired variables was used for comparing the values after the first infusion (baseline ${ }_{2}$ ) with those 20 minutes after the second.

\section{Results}

BASELINE VALUES AND AUTONOMIC BLOCKADE The Table shows the mean values of the physiological measurements both before (baseline 1) and after (baseline 2) the first infusion. Good reproducibility was observed between these values. Mean cardiac output was slightly lower before dihydralazine $25 \mathrm{mg}$ reflecting diminished stroke volume and heart rate. The autonomic blockade induced several distinct

$$
\begin{array}{|cc|}
\hline \begin{array}{c}
\text { 6.25mg + autonomic } \\
\text { blockade }
\end{array} & \Delta 25.0 \mathrm{mg} \\
\text { Autonomic blockade } & \square 12.5 \mathrm{mg} \\
\text { alone } & 06.25 \mathrm{mg} \\
\hline \text { * Placebo alone } & \\
\hline
\end{array}
$$

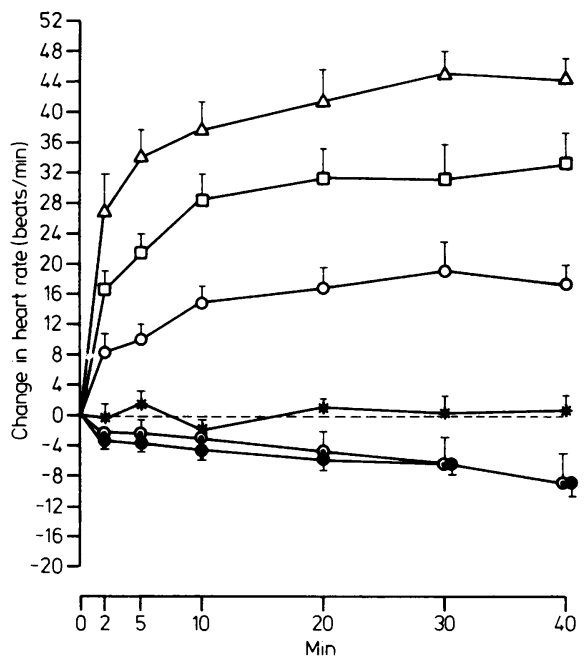

Fig. 1 Changes in heart rate from values after first infusion (baseline 2; zero time point) with various intravenous doses of dihydralazine, autonomic blockade alone, and placebo alone. Values are mean $(S E M)(n=6)$. haemodynamic reactions: an increase in heart rate and blood pressure and pronounced prolongations of the heart rate corrected systolic time intervals. At $\mathbf{4 0}$ minutes after the first infusion (baseline 2) both autonomic blockade alone and placebo alone produced minor variations in the values. This reflects the stable haemodynamic situation with autonomic blockade as well as at rest without the influence of drugs.

\section{TIME SEQUENCE OF DRUG EFFECTS}

The time course of the effects of dihydralazine is illustrated by the changes in heart rate (Fig. 1), which clearly shows a dose dependent increase. The rapid increase virtually reached its maximum after 20 minutes. Autonomic blockade eliminated the effect of dihydralazine on heart rate: with the combined treatment the pattern was virtually identical to that after autonomic blockade alone (Fig. 1). The effects on the other haemodynamic indices were similar: Fig. 2 shows only the results at 20 minutes after dihydralazine.
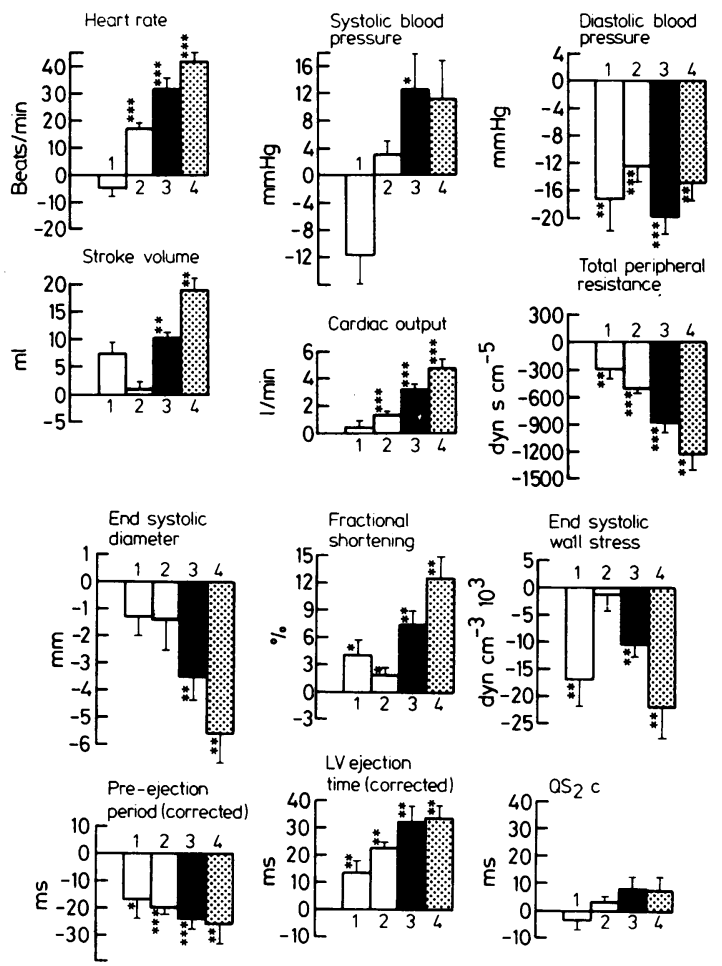

Fig. 2 Haemodynamic changes from values after first infusion (baseline 2) with various doses of dihydralazine measured 20 minutes after intravenous infusion. Values are mean (SEM) $(n=6)$. Dihydralasine doses: 1, $6.25 \mathrm{mg}$ plus autonomic blockade; 2, $6.25 \mathrm{mg} ; 3,12.5 \mathrm{mg} ; 4,25.0 \mathrm{mg} ; Q S_{2} c$, corrected electromechanical systole. ${ }^{\star} p<0.05 ;{ }^{\star \star} p<0.01$; $\star \star \star p p<0.001$. 
HAEMODYNAMIC CHANGES

Systolic blood pressure (Fig. 2) tended to rise with dihydralazine; with autonomic blockade the small rise which followed $6.25 \mathrm{mg}$ dihydralazine alone became a pronounced decrease. Diastolic pressure fell appreciably, independent of the effects of dihydralazine or autonomic blockade. Stroke volume increased in relation to dose after dihydralazine, the effect of $6.25 \mathrm{mg}$ being intensified by autonomic blockade. After dihydralazine cardiac output increased in relation to dose and total peripheral resistance decreased appreciably (for both indices the effect was dampened by autonomic blockade). End systolic diameter and end systolic wall stress were appreciably reduced in relation to dose by dihydralazine (the latter effect being accentuated by autonomic blockade), whereas fractional shortening was increased progressively by dihydralazine (autonomic blockade potentiates the effect of dihydralazine) (Fig. 2). End diastolic diameter after autonomic blockade was reduced by $0.14 \mathrm{~cm}$ and after dihydralazine showed varied changes unrelated to dose. The systolic time intervals show a dose dependent shortening of heart rate corrected preejection period and a prolongation of the heart rate corrected left ventricular ejection time; autonomic blockade reduced these effects. The minor changes in $\mathrm{QS}_{2} \mathrm{c}$ did not reach statistical significance.

\section{SIDE EFFECTS}

The. $25 \mathrm{mg}$ dose of dihydralazine caused palpitation, and at the end of the test period, when the subject stood up orthostatic problems occurred. Furthermore, headache developed and lasted several hours in all subjects. The $12.5 \mathrm{mg}$ and $6.25 \mathrm{mg}$ dihydralazine doses produced minor side effects which were less intense after autonomic blockade.

\section{Discussion}

The actions of dihydralazine on the cardiovascular system are partly due to direct drug effects and partly caused by reflex responses. The primary action is the direct relaxation of the vascular smooth muscle; since the effect on the arterioles is much greater than on the veins ${ }^{17-19}$ its action can be regarded exclusively as reducing afterload. The reflex responses to dihydralazine are an increase in sympathetic tone and a decrease in vagal effects. These lead to tachycardia and presumably to indirect inotropic and other cardiac effects. The direct inotropic effects of dihydralazine had been excluded. ${ }^{20}$ After the administration of this drug in laboratory animals or man blood pressure (diastolic $\gg$ systolic) and peripheral vascular resistance fell. ${ }^{1819}$ These effects are responsible for the above reflex response, which is evident from the heart rate increase; blood pressure and total peripheral resistance also reflect these effects. There is some increase in systolic blood pressure, which as seen from the results after autonomic blockade, is dependent on the reflex activity. The reduction in systolic blood pressure is intensified with autonomic blockade, which depresses the effects of dihydralazine on cardiac output. The peripheral vasodilatation caused by dihydralazine reduces ventricular afterload and thereby improves emptying of the left ventricle. This produces an increase in pump performance, as is seen from the effects on end systolic wall stress, end systolic diameter, fractional shortening, stroke volume, and cardiac output.

The primary intrinsic responses produced by dihydralazine, as seen from the results after autonomic blockade, are a fall in both systolic and diastolic blood pressure and total peripheral resistance and a pronounced reduction in afterload with a consequent increase in stroke volume and fractional shortening. The reflex mediated increase in heart rate was abolished completely after autonomic blockade. Nevertheless, even with autonomic blockade the reflex responses were not eliminated completely, and the reduction in dihydralazine's effect on total peripheral resistance might signify an increase in alpha sympathetic tone. This would indicate that the vessel walls' sensitivity to alpha mimetic influence is still present despite dihydralazine's vascular relaxing effect. Nevertheless, the effect of dihydralazine with autonomic blockade reduced the increase in cardiac output and therefore might also be responsible for the decrease in total peripheral resistance.

It is clear that the reductions in afterload and diastolic blood pressure after dihydralazine lead to shortening of the heart rate corrected pre-ejection period. The heart rate corrected left ventricular ejection time is prolonged after dihydralazine; this parallels the increasing stroke volume and even more so the reduced peripheral resistance. Because of the opposing effects of dihydralazine on these indices the $\mathrm{QS}_{2} \mathrm{c}$ is only minimally changed ( $<10 \mathrm{~ms}$ ), being lengthened rather than shortened. The effect of dihydralazine on systolic time intervals is only slightly modified by autonomic blockade. Despite the lowered diastolic blood pressure, the shortening of the heart rate corrected pre-ejection period was limited and may be primarily attributed to propranolol's beta blocking action followed by attenuation of the noradrenergic effects. The changes in heart rate corrected left ventricular ejection time with autonomic blockade confirm the suggestion that this index mainly reacts to changes in peripheral resistance. These results contrast with those of a previous study by Buch et $\mathbf{a l}^{6}$; they found a significant shortening of all systolic time intervals (including $\mathrm{QS}_{2} \mathrm{c}$ ) after administration of the beta $_{2}$ mimetic drug terbutaline. Since this drug's 
effects were the same even with atenolol-a partial beta $_{1}$ antagonist-the conflicting results from the two studies could indicate the existence of beta ${ }_{2}$ receptors in the human heart as suggested previously. ${ }^{7}$ The results with terbutaline could be easily explained by both vasodilation (via beta ${ }_{2}$ stimulation in the vascular smooth muscle) and positive inotropic effects.

\section{CONCLUSIONS}

Afterload reduction leads to a clear pattern of changes in systolic time intervals: heart rate corrected preejection period is shortened, heart rate corrected left ventricular ejection time is prolonged, and $\mathrm{QS}_{2} \mathrm{c}$ is nearly unchanged. This pattern is only slightly changed after blockade of autonomic reflex activity.

HCS was a Paul Martini Stifting research fellow (1982-3).

\section{References}

1 Lewis RP, Rittgers SE, Forester WF, Boudoulas H. A critical review of the systolic time intervals. Circulation 1977; 56: 146-58.

2 Weissler AM, Harris WS, Schoenfeld CD. Systolic time intervals in heart failure in man. Circulation 1968; 37: 149-59.

3 Buch J, Egeblad H, Hansen PB, Kjaergård H, Waldorff $S$, Steiness E. Correlation between changes in systolic time intervals and left ventricular end-diastolic diameter after preload reduction. Non-invasive monitoring of pharmacological intervention. $B r$ Heart $\mathcal{f} 1980 ; 44$ : 668-71.

4 Harris WS, Schoenfeld CD, Weissler AM. Effects of adrenergic receptor activation and blockade on the systolic preejection period, heart rate, and arterial pressure in man. F Clin Invest 1967; 46: 1704-14.

5 Leighton RF, Zaron SJ, Robinson JL, Weissler AM. Effects of atrial pacing on left ventricular performance in patients with heart disease. Circulation 1969;40: 615-22.

6 Buch J, Waldorff S, Hansen PB, Rasmussen OO. Noninvasive measuring of the circulatory effect of afterload reduction in order to monitor the pharmacodynamic effect of drugs in normal volunteers. Br Heart $\mathcal{F}$ 1983; 50: $170-5$.
7 Brown JE, McLeod AA, Shand DG. Evidence for cardiac $\beta_{2}$-adrenoceptors in man. Clin Pharmacol Ther 1983; 33: $424-8$.

8 José AD, Taylor RR. Autonomic blockade by propranolol and atropine to study intrinsic myocardial function in man. $f$ Clin Invest 1969; 48: 2019-31.

9 Belz GG, Aust PE, Belz G, Appel E, Palm D. Sympathomimetic effects of amezinium on the cardiovascular system and plasma catecholamines in man. Eur $\mathcal{J}$ Clin Pharmacol 1982; 23: 15-20.

10 Belz GG, Aust PE, Schneider B. Time course of the effects of single intravenous doses of digitoxin and digoxin in normal volunteers. I Cardiovasc Pharmacol 1981; 3: 1116-25.

11 Belz GG, Riedlinger G. Nichtinvasive Untersuchungen zur kardialen Wirkung niedriger DigitoxinErhaltungsdosen. Z Kardiol 1980; 69: 296-306.

12 Teichholz LE, Kreulen TH, Herman MV, Gorlin R. Problems in echocardiographic volume determinations: echocardiographic-angiographic correlations in the presence or absence of asynergy. Am $\mathcal{F}$ Cardiol 1976; 37: 7-11.

13 Bayer O, Loogen F, Wolter HH. Die Herzkatheterisierung bei angeborenen und erworbenen Herzfehlern. 2nd ed. Stuttgart: G Thieme, 1967:57.

14 Feigenbaum H. Echocardiography. 3rd ed. Philadelphia: Lea and Febiger, 1981:119-24.

15 Grossman W, Braunwald E, Mann T, McLaurin LP, Green LH. Contractile state of the left ventricle in man as evaluated from end-systolic pressure-volume relations. Circulation 1977; 56: 845-52.

16 Reichek N, Wilson J, Sutton MSJ, Plappert TA, Goldberg S, Hirshfeld JW. Noninvasive determination of left ventricular end-systolic stress: validation of the method and initial application. Circulation 1982; 65: 99-108.

17 Freis ED, Rose JC, Higgins TF, Finnerty FA Jr, Kelley RT, Partenope EA. The hemodynamic effects of hypotensive drugs in man. IV 1-hydrazinophthalazine. Circulation 1953; 8: 199-204.

18 Koch-Weser J. Vasodilator drugs in the treatment of hypertension. Arch Intern Med 1974; 133: 1017-25.

19 Blaschke TF, Melmon KL. Antihypertensive agents and the drug therapy of hypertension. In: Gilman AG, Goodman LS, Gilman A, eds. Goodman and Gilman's The pharmacological basis of therapeutics. 6th ed. New York: Macmillan, 1980:793-818.

20 Chatterjee K. Hydralazine in heart failure. Herz 1983; 8: 187-98. 